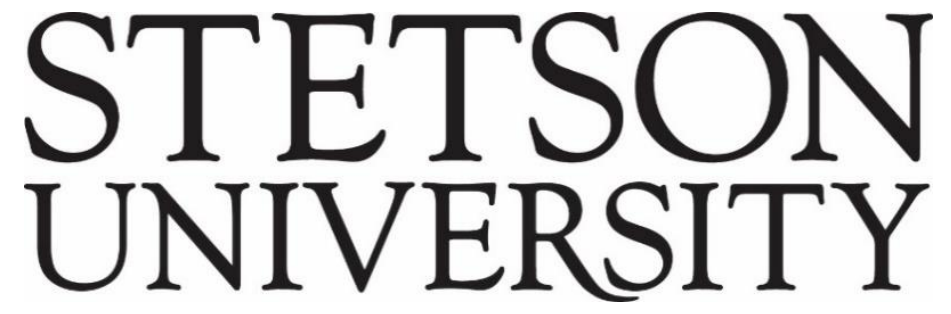

Voices of Reform: Educational Research to Inform and Reform

Volume $3 \bullet$ Issue $2 \bullet$ Article 6

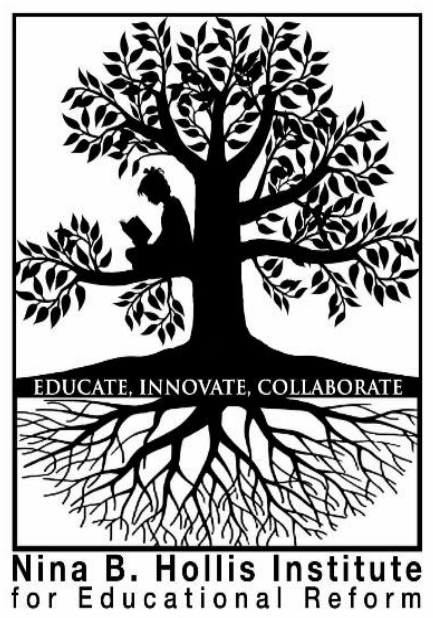

December 2020

\title{
Understanding the Emotional Systems in Schools
}

Jeffrey Hartmann

Stow-Munroe Falls City Schools

Follow this and additional works at: http://www.voicesofreform.com

Recommended Citation

Hartmann, J. (2020). Understanding the emotional systems in schools. Voices of Reform, 3(2), 118-132. Retrieved from https://www.voicesofreform.com/article/18598-understanding-the-emotional-systems-in-schools doi:

$10.32623 / 3.10008$

http://dx.doi.org/10.32623/3.10008

Revisions

Submission date: January $28^{\text {th }}, 2020$

$1^{\text {st }}$ Revision: April $16^{\text {th }}, 2020$

Acceptance: June $27^{\text {th }}, 2020$

Publication date: December $29^{\text {th }}, 2020$ 


\title{
Understanding the Emotional Systems in Schools
}

\author{
Jeffrey Hartmann ${ }^{1}$
}

\author{
${ }^{1}$ Principal \\ Stow-Munroe Falls City Schools, Stow, Ohio, United States \\ jeffrey.hartmann@gmail.com
}

\begin{abstract}
There is a hidden dynamic in schools that is potent, pervasive, and impacts all aspects of a school's function. This dynamic exists among those within a school and has the power to propel or thwart improvement efforts, include or exclude new staff members, and be a help or hindrance to the mental well-being of our educators. Revealing this hidden world and understanding its impact is key to moving schools forward. What follows are examples of how our school used a conceptual framework known as Resilient Leadership, based on Bowen Family Systems Theory, to help our team better understand this hidden world as we moved forward. Our school needed a framework to help everyone navigate the emotional tumult that inevitability occurs through the process of improvement.
\end{abstract}

\section{Keywords}

educational leadership, organizational change, systems theory, stress

\section{Introduction}

School improvement has been widely researched since the launch of Sputnik in 1957 (Finley, 2000; National Defense Education Act, 1958). Each program, initiative, and policy has aimed to improve student achievement and has created "more education policies...than the whole prior history of schooling back to ancient Greeks" (Loveless, 1998, p. 283). Woods (2002) put a finer point on this when he states that school improvement has, "Engaged frequently in a variety of unrelated activities at... school sites intended to help raise student achievement" (p.32). These "unrelated activities" typically focus on the technical aspects of a teacher's practice, sometimes forgetting that, “...teachers' humanness is very much a part of their practice... and teachers need expressions of personal regard and support as much as anyone else does" (Bryk \& Schneider, 2002, p. 27). It is the intersection of the technical aspects and the emotional systems that is the focal point of Resilient Leadership. 
Resilient Leadership examines the recursive nature of emotional systems response to rational, technical, processes. Much of the literature related to change leadership seem to focus on the technical work of improving organizations through structures, processes, strategies, or vision creation. Other work approaches change as a culture-building enterprise, creating feelings of momentum, celebrating small victories, and embracing positivity and resiliency throughout the firm. For instance, in John Kotter's book, Leading Change (1995), he speaks to vision creation, strategy development, and stages of the change process. In Jim Collin's book, Good to Great (2011b), he, too, discusses a variety of structural approaches to improving organizations. Collins speaks to establishing a culture of success, getting the right people in the right positions, and the actions that good leaders take to move organizations forward. Collins and Kotter speak to the technical elements that leaders can make to cultivate change. There is no allowance of the emotional systems that are activated within individuals or groups when there is a move from the status quo.

Tony Wagner, in his book, Change Leadership (2012), gets closer to understanding the emotional processing that occurs in a change environment. Wagner provides a quote from a school administrator that addresses her hesitation regarding the school's change approach. The individual says, "I fear that I would be held accountable for the success and failures of the teachers as instructional leaders" (p. 86). Wagner then continues about "competing commitments" that may be at odds with change initiatives and how to overcome those roadblocks. However, Wagner does not engage with the emotional systems that underpin this particular administrator's anxiety. By avoiding the administrator's personal anxiety, her emotional bandwidth between processing the "competing commitments" that Wagner mentions and the personal processing of the change experience.

Resilient Leadership makes central the connection between the technical elements in the rational world and the emotional reactions that follow. If leaders take action to move schools from "good to great," there is an emotional reaction that will surely follow. Kotter, Collins, and Wagner provide advice for leaders to persist with improvements amidst the various forms of pushback. They do not, however, address why that pushback occurs in the first place. Resilient Leadership provides some understanding of this dynamic, giving leaders even further insight when managing change.

\section{Local Context}

Constructed in 1986, Stow-Munroe Falls High School merged two other high school-level buildings, the former Workman School, built in 1924, and the former Stow Senior High School, now Lakeview Intermediate School, built in 1960. For over three decades, students and teachers in grades 9-12 were in separate buildings: 9 and 10 in Workman and 11 and 12 at Stow High School, now Lakeview (Hanson, 1987). Each school developed its own culture, expectations, teaching styles, and the like. In 1986, the community began construction on a new high school to consolidate grade levels 9-12 into one location (Figure 1). 
Figure 1. Stow-Munroe Falls High School, Built in 1986

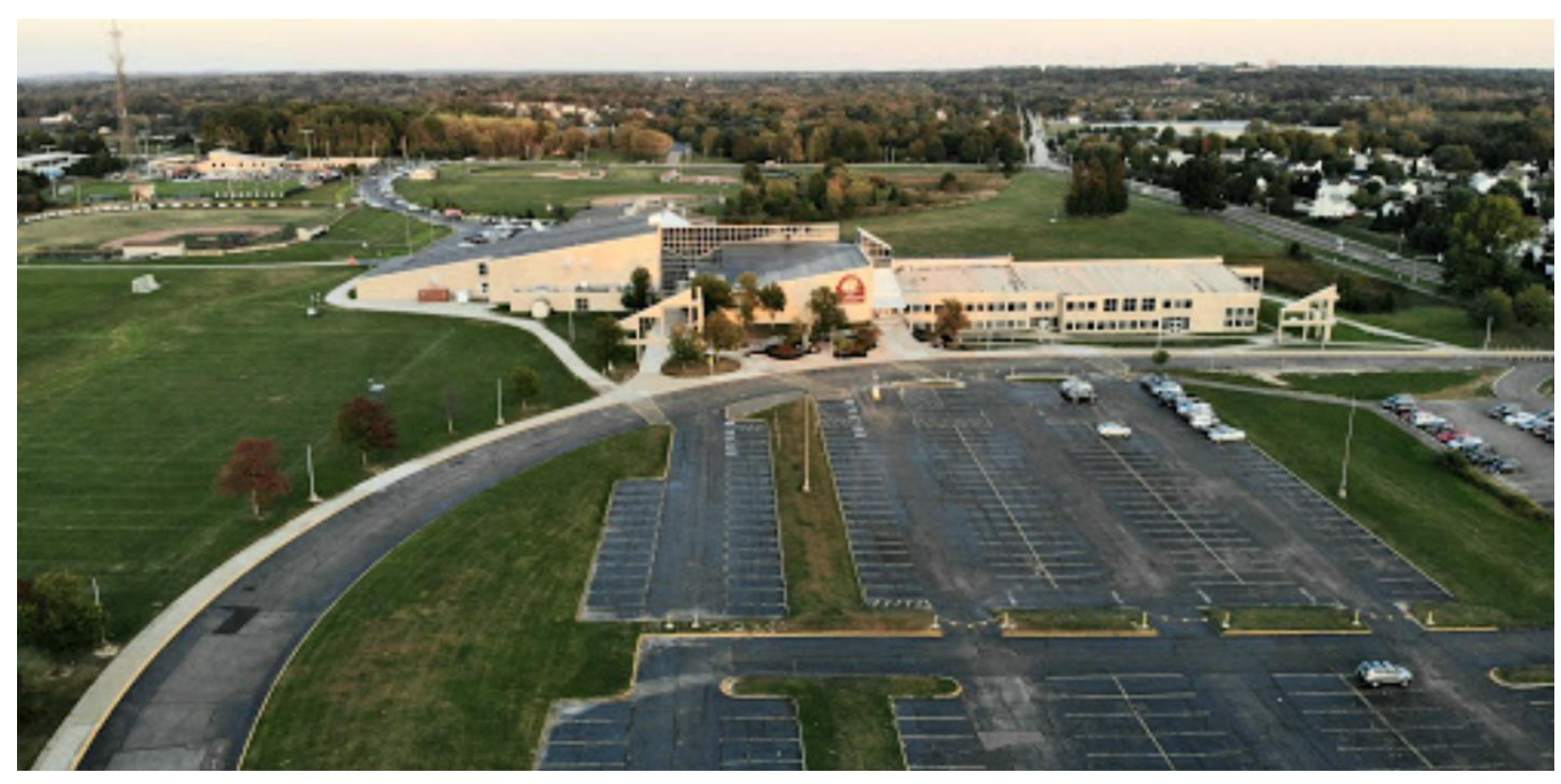


When the school opened, it instantly became the largest high school in our county. On the first day of school, two faculties came together and now number over 120 professionals, each with their conception of what effective practice looked and sounded like. The new school had a single overall principal, four assistant principals, five school counselors, and department chairpersons. In speaking with current and former faculty who were present for the merge, management at the time did little to bridge the two cultures. Since opening in 1987, teachers at SMFHS continued to work with kids but have done so in relative isolation, which left traditions, mindsets, and practices that were present in either Workman or Lakeview to persist.

Like many other districts in the country, our school system weathered a myriad of improvement initiatives that were both attempted and stalled. There was Working on the Work, Character Counts, International Baccalaureate, conversations about grading and assessment practices, and the like. There was never a high school-specific, school-wide focus to improve that applied to everyone. The organizational inertia was strong. Our teachers expected to be left alone and teamwork was an anathema. Conversations about testing and student data were non-existent. We also lacked the space in our schedule to have a routine time to work through these issues. We had passionate educators who wanted to prepare students better, but the emotional systems in place were robust and entrenched. These established norms regarding teacher autonomy delimit the ability of a school to engage in organizational change (Bryk \& Schneider, 2002). As a result, when I arrived as principal in 2015, I believed that I had inherited the most extensive collection of independent educational contractors in Ohio.

This context underscores the depth to which staff held beliefs, practices, and traditions. The more deeply held these beliefs, the higher the risk when you ask staff to change some of those beliefs. Asking someone to change can provoke an emotional response akin to the grief process after a severe loss (Heifetz \& Linsky, 2002). Along the way, all teachers have bestowed unto them a set of practices or beliefs about their practice. Often, this bestowal comes from a trusted or revered colleague or friend. When we ask people to change or improve, we are, in essence, asking them to break their loyalty to the person or place that bestowed that belief set in the first place. Understanding this deep emotional connection was very important for me as a new school principal trying to move a building forward that had not ever experienced change. Collectively and individually, we lacked the skill sets to successfully navigate the emotional tumult associated with change. The conceptual models within Resilient Leadership were applied by many with the help of our Resident Leadership coach, who became a crucial guide on our improvement journey. I have often said that we would not have been able to undertake the degree of change without Resilient Leadership walking alongside.

Resilient Leadership is a framework established by Bob Duggan, Jim Moyer, and Bridgette Theurer in their books Resilient Leadership (2010), and Resilient Leadership 2.0 (2017). The goal of Resilient Leadership is to improve a person's or a system's emotional differentiation. A basic definition of emotional differentiation is an individual's ability to separate thinking from feeling (Kaslow \& Figley, 1995). In groups, emotional differentiation is marked by people who engage in behaviors that reinforce individuality versus togetherness. In our school, we focused on four critical elements from Resilient Leadership with the most potential to support our improvement: 
1) the concepts of the rational system and the emotional system, 2) over and under-functioning, 3) being a step-down transformer, and 4) relationship triangles.

Our work began when our Resilient Leadership coach, John Moyer, started to present during professional development sessions for our school district. These sessions were always well attended and many faculty members spoke highly about the utility of the Resilient Leadership framework and what John was sharing. John then started to hold book studies and then branched into individual leadership development sessions for teachers in our building. Soon, the district leadership asked for John to provide his services district-wide to any interested teacher or administrator. The Resilient Leadership 2.0 book joined other supporting texts to form the "canon" of our school improvement program. Our teachers and leaders began using the language and concepts, some of them mentioned below, in their daily work. From my view as the school leader, the conceptual framework and language introduced to our staff gave everyone a common lexicon to understand contexts and relationships. In so doing, it reduced anxiety because the staff was better able to identify what they were feeling and why.

\section{Emotional and Rational Systems}

One of the first instructive experiences I had was understanding that there was a whole world that was invisible but reacted directly with the tangible world in front of me. We term these two worlds as the "emotional system" and "rational system," respectively (Figure 2). Rational world changes include, but are certainly not limited to, policies, procedures, evaluation frameworks, shifting priorities, and the like. Change efforts are often limited to the rational world: new curricula, teaching techniques, technology, procedures, etc. These rational world changes often have a direct emotional system reaction both within an individual and within a group. The Resilient Leadership framework aims to grow the capacity of individuals to reduce their emotional responses, reducing system anxiety regardless of the stressor. The Resilient Leadership authors explain that the internal feeling of being off-balance is considered a form of reactivity. Being able to be thoughtful amid heightened anxiety is known as emotional differentiation. Essentially, emotional differentiation suggests that individuals have more than one method of coping with change, thus keeping their chronic anxiety in a state of balance (Duggan \& Moyer, 2010). Emotionally differentiated individuals can stop, think, and respond in a thoughtful way to a change. Individuals with less emotional differentiation, however, provide an automatic, immediate and less thoughtful, reaction to a change.

The earliest example of the emotional system in action was when we needed to change procedures for teacher parking on campus. At the end of the school day, students at a nearby middle school were loading onto buses to head home. When the buses started to leave the parking lot, a student who was riding a skateboard fell off and landed in the path of a school bus, which then rolled over him (Jenkins, 2016). The student died as a result of this unfortunate accident. Wishing to avoid the same tragedy, the district operations department and the high school leadership team decided to relocate the bus loading area. Previously school buses, student drivers, staff members, and parents picking up students, all shared the same section of the driveway in front of the school. To increase safety, we moved the busses to another parking lot on campus, away from the rest of the traffic flow. We engaged in a rational world change, moving the parking lot, which sparked a 
predictable reaction in the emotional system. The reactivity manifested itself through faculty meetings called to discuss parking specifically, individual lobbying efforts made to school administrators, and activated union networks to stop or slow this change. Teachers said it was too far to walk from the main parking lot. They also noted that many staff members have mobility issues and handicapped placards. There was also concern about safety in the morning with lighting and ice. Time spent in traffic with "everyone else" would make teachers late for class, thereby compromising instructional quality. The parking lot change moved forward, and the culture adjusted, but not until we weathered a fair amount of reactivity from aggrieved faculty.

Organizationally, reactivity makes visible the value sets, traditions, thinking, and other hidden aspects of the organization. Revealing these dynamics is essential so that leaders can identify a starting point for diagnosing a problem. Reactivity can give leaders a glimpse of the collective emotional differentiation within the organization. As leaders move about the organization, it is imperative to pay attention to the micro-interactions with staff to clearly "see." Hostile or combative language, the number of people speaking (or not speaking), and body language are often more insightful than the architecture of the proffered arguments. Heifetz, Grashow, and Linsky (2009) call this "listening to the song beneath the words" (p. 76). Having a clear sense of an organization's emotional differentiation is a critical part of understanding how much collective stress the system can handle. The story about the parking lot helped reveal the value sets, traditions, and thinking in existence at the time. While managing the reactivity was not a pleasant experience (it rarely is), it revealed a profound lack of emotional differentiation within the school. This lack of emotional differentiation, however, is not endemic to our high school.

Teacher anxiety and stress rates are well-researched, international phenomenon (Sabina, 2014; Skaalvik \& Skaalvik, 2017; Steinke, 2018; Travers \& Cooper, 1993). The multiple, ever-changing policy and practice expectations that educators face take a heavy emotional toll and contribute to high amounts of anxiety and eventual teacher burnout (Yong \& Yue, 2007).

We see the deleterious effects of stress with productivity decline and job satisfaction trending downward, resulting in otherwise good teachers feeling forced to leave the field (LaRocco et al., 1980). Conversely, teachers who can regulate emotions and, by extension anxiety, display a higher job satisfaction and positive affect (Brackett et al., 2010). As Jones, et al., (2013) states, "Teachers who are calm, positive, and content are likely to be better equipped to treat students warmly and sensitively, even when students behave in challenging ways" (p. 63). The conceptual frameworks presented in Resilient Leadership assist educators in understanding these multiple stressors and should be given the same priority as pedagogical theory in teacher preparation programs. 
Figure 2. Rational and Emotional Systems Iceberg as depicted in Resilient Leadership 2.0 (p. 6)

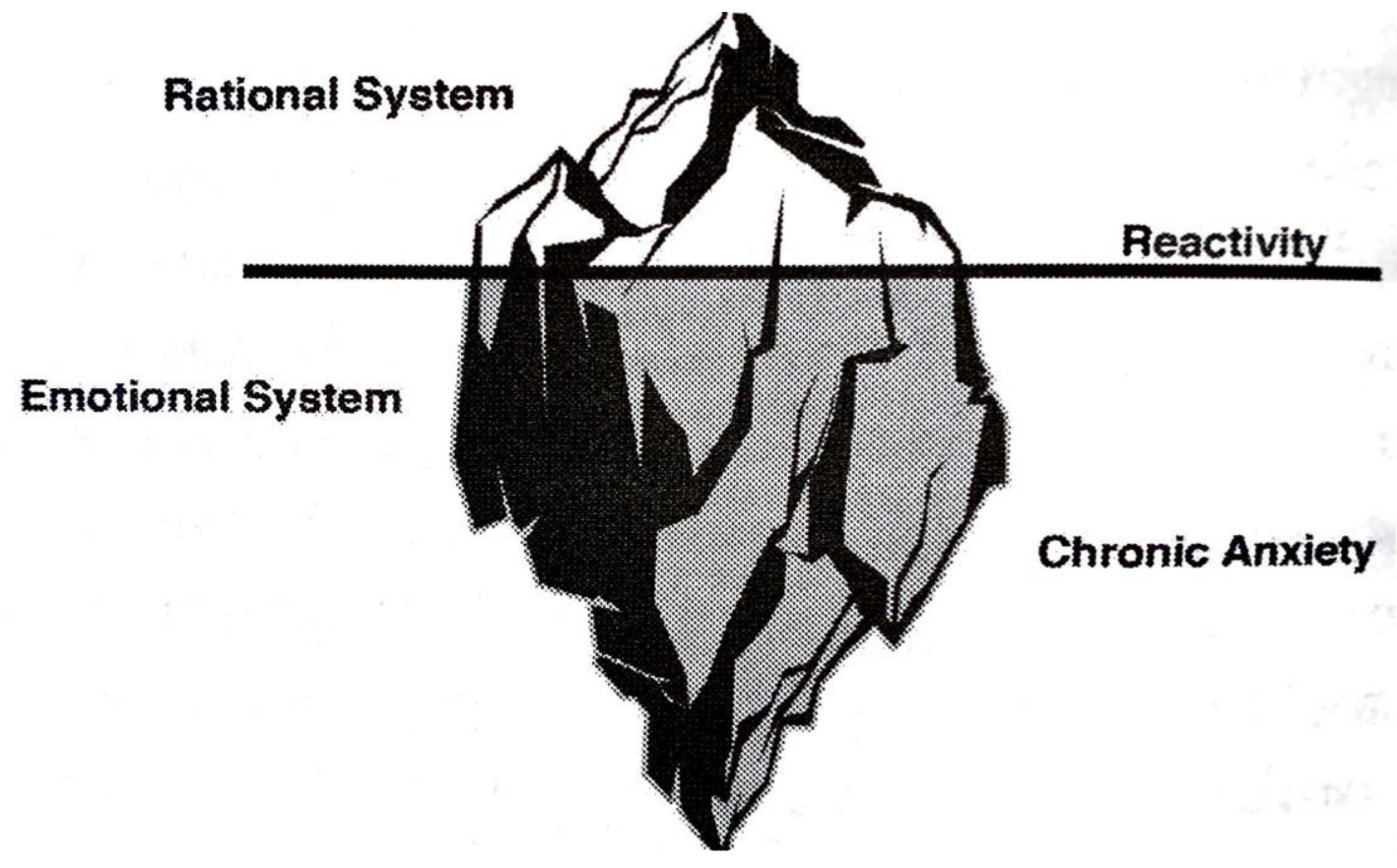




\section{Over-and-Under Functioning}

Over-functioning is generally regarded as the reciprocal relationship where one person or group is overly responsible while another person or group is irresponsible. At a meeting with union representatives one afternoon, they provided a list of chronic areas of improvement. The topics had titles like "morale is low," "communication is poor," and "leadership visibility." When I asked for more specifics, the representatives were not able to share anything further. I then asked the representatives to come to the meeting with a few proposed solutions so that, as a team, they could work together to solve problems. At another meeting a month later, the same issues were presented with no proposed solutions. We had an uncomfortable meeting because the representatives were waiting for me to offer solutions, as had been custom for previous administrators. I declined to provide answers, however. A few days later, I individually spoke with a few members of the union's team. These impromptu meetings were important because they helped explain my thinking and assisted in my understanding of the block to offering solutions. For the better part of a decade, the union vice president worked closely with the building administration, and building representatives were mostly ceremonial. When a changeover in the union vice president position occurred, an elementary-level teacher filled the position. As a result, the high school administration had to work with building representatives who never had to exercise leadership before. The individual interactions that I had in between these meetings were necessary. These one-on-one sessions helped build their capacity as leaders so that the roles of the team equalized, and effective collaboration could take place. In a subsequent meeting, the representatives came with proposed solutions to the problems, and the team found resolution on an equal footing.

In another example, we work with many teachers who seem entrenched in traditional grading practices. This is usually apparent when the teacher has over 100 assignments in a given marking period. When asked, the teachers say that this is how they were taught, how they have conducted their grading practices for years, or that the "students won't do anything if they don't get points." The teachers think that their grading approach is appropriate; "students want points, so I'll give them opportunities to get points," or so the thinking goes. However, this traditional notion of grading treats students more like cogs in a grading machine instead of learners. My teacher gives me an assignment; I complete it; he gives me points. The level of learning taking place in this scenario is questionable but all too familiar for schools. While the teacher is over-functioning with this practice, the students have been given tacit permission to under-function. Changing this dynamic will cause dissonance and discomfort. As the teacher grapples with researching and testing new grading approaches, he or she will also weather the reactivity from students and parents who are all too accustomed to equating more points with more learning.

To level out the functioning of individuals, we need to engage in new learning experiences to build capacity (Collins, 2011a, 2011b). This build is not linear, not rapid, and has a significant amount of emotional processing involved. To encourage an under-functioning individual or group to move beyond their current parameters requires a challenge which disrupts the emotional system mentioned earlier. Given the myriad of changes that educators experience, it is unsurprising why teachers sometimes want someone else to solve a problem (Heifetz \& Linsky, 2002). By not equalizing the functioning of all members of the organization, the organization itself will remain 
locked in a cycle of failure and frustration. In other words, parking lots remain the same despite student safety, and grading undercuts authentic learning experiences.

\section{Step-Down Transfer}

During times of organizational stress, interactions among people and groups can become tense as they search for resolutions or determine where to place blame or both. Resilient Leadership speaks of leaders as "step-down transformers," an analogy to the role of these devices play as part of our power grid. Members of any social network have the power to increase or decrease the anxiety within that social network. When others engage in gossip, raise voices, shout, or display hostile body language, they are adding anxiety to the system. In effect, they are acting as a step-up transformer. Step-down transformers remain calm amid stress, provide thoughtful responses, and ask thoughtful questions.

One morning, one of my leadership colleagues attended a department meeting regarding the emotionally charged topic of final assessments. The department was comprised teachers with a high degree of reactivity amongst the group. During the meeting, teachers lobbed question after question to her while she responded in a thoughtful and calm tone. Internally, her anxiety was rising, but she knew that if she reacted with an equal level of emotion, she could have increased the negative momentum within that network. Instead, she stayed connected by listening to our teachers and weathered the storm. Regardless of how much of an emotional crescendo that may take place, she was determined to explain her thinking calmly, show others how to respond constructively, and not add to the negative momentum around this topic. Understanding one's emotional state and whether one can act as a step-down transformer is a vital element of selfawareness and a critical skill for all members of a system to exercise.

\section{Triangles}

Triangles exist everywhere, and when the system or network is calm, they remain invisible. When under stress, however, triangles are more clearly seen. In his book, Failure of Nerve, Ed Friedman (2007) expands on the idea of emotional triangles that form between three individuals or between two individuals and an issue (Friedman, 2007, p. 207). As a noun, triangles are normal and natural occurrences between people. Leveraging relationships into the action of "triangling" or being "triangled" is when the caustic effect of triangles emerge (Steinke, 2018). Figure 2 provides a basic example wherein the boss (A) is attempting to manage the conflict between direct report B and direct report $\mathrm{C}$. It is natural for people under duress to seek out allies to find acceptance and validation that one's point of view is the "correct" one. By engaging in the action, however, individuals have "triangled" others in their social network. Triangles form most often when organizational stress increases, and schools are no exception to that phenomenon. The points of the triangle may be labeled differently depending on the scenario. For example, there could be a conflict between two teachers over a particular teaching strategy. The two teachers become points $A$ and $B$ with the teaching strategy becoming point $C$. In another example, parents (point A), could have a problem with a teacher (point B), and then speak to the principal (point C). 
Triangles are predictable and "light up" when controversy takes place in a school. In personnel action scenarios, the individual being held accountable (A) by the principal (B) seek out a third person $(\mathrm{C})$ to find validation and share his/her side of the story. One afternoon, one of my assistant principals was working in her office when a teacher stopped by and started talking about the person recently placed on administrative leave. These comments seemed to come from nowhere. She soon realized that the teacher on administrative leave had many friends in the building who were speaking on his behalf and advancing his cause for reinstatement. Being "triangled" is now part of our school-wide lexicon. We have all been caught in them and often realize it after the fact. Having this awareness during the act of "triangling" better guides comments and actions during the conversation. Every problem a leader faces can be illustrated via a triangle. They exist everywhere and often where you least expect them.

Figure 3. Emotional Triangle Representation from Resilient Leadership 2.0 (p. 101)
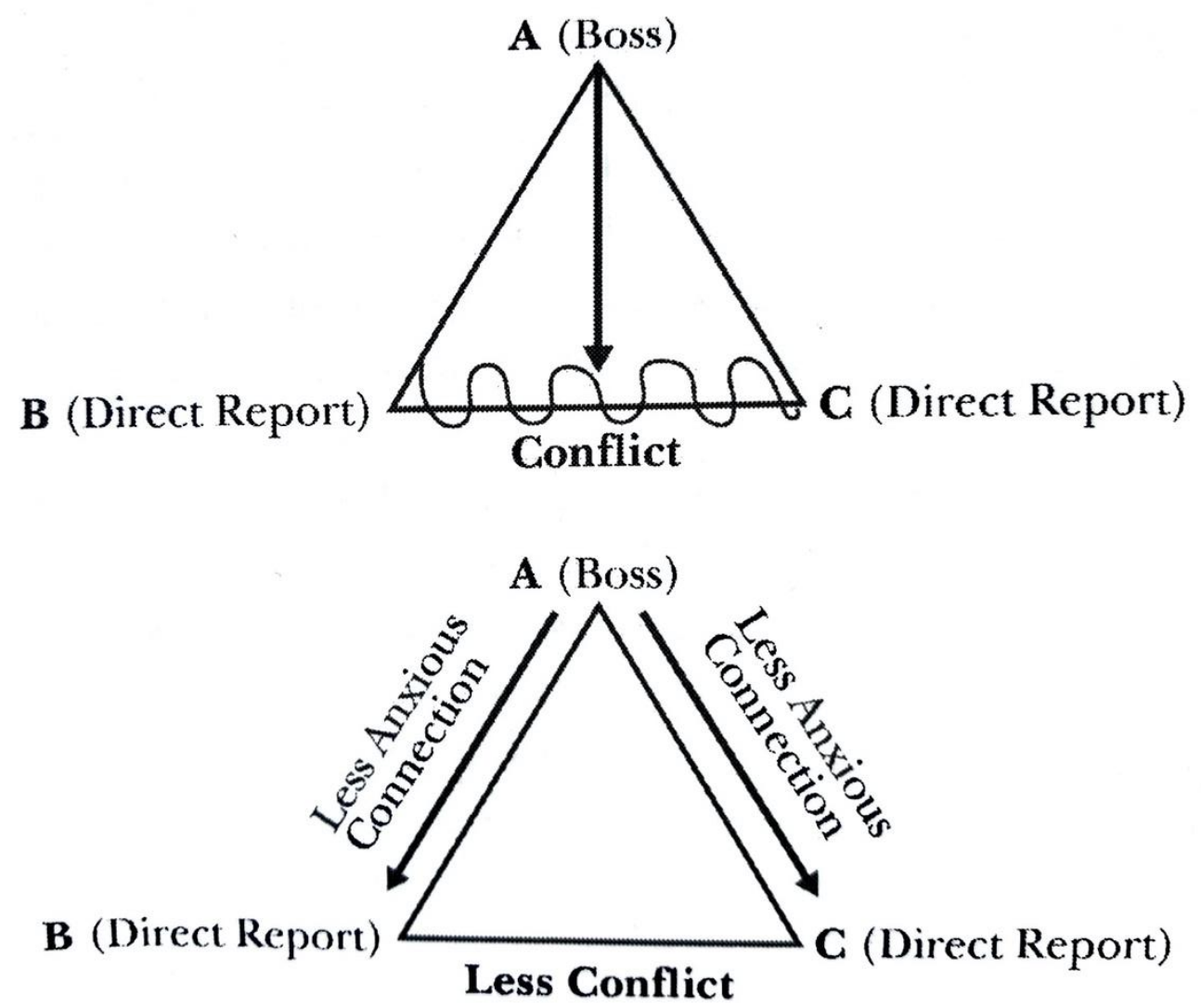


\section{Implications for Practitioners}

Jennings and Greenberg (2009) speak to the idea that teachers who have a higher degree of socialemotional competence tend to have more positive student relationships and a healthier classroom climate, which in turn, creates positive student outcomes. Moreover, supporting high student achievement requires teamwork and coordination of efforts rather than the traditional notions of educators as independent contractors (Hartmann, 2013). Interdependence replaces independence. The Resilient Leadership framework has supported our change initiatives since 2015, bringing people together, focusing our efforts, and guiding us through a hidden world that often thwarts school improvement.

Ohio's schools are not alone as they face a constant set of changing parameters that impact their work with kids. This state has witnessed some jarring accountability changes, all taking place since 2014. In the accountability realm, Ohio moved from the Ohio Gradation Test (OGT) to the Ohio State Tests (OST) based first on the PARCC framework via Common Core and now based on the American Institutes of Research (AIR) framework. For teacher evaluation, the Ohio Department of Education (ODE) released the Ohio Teacher Evaluation System (OTES) in 2015 with a revision published in 2020. Schools in this state also grapple with open enrollment, the idea that a student can live in one district and attend another, with the student's tax dollars following him or her. Putting this on steroids is the Education Choice Scholarship Program, introduced in the 2019 budget bill, that allows tax dollars to support students to private and religious institutions if their home school is on an "Ed Choice" list. As of January 2020, 899 of the 1,227 schools in Ohio are deemed "Ed Choice" schools. To round out the systemic stressors in Ohio is the unconstitutional school funding system. Since 1991, the Ohio school funding formula has been ruled unconstitutional in four separate cases (Urycki, 2017). In the most recent State Supreme Court case, however, the justices declined to provide a solution. Schools and teachers continue to work through financial uncertainty with tax levies and layoffs a routine part of public-school life. All of these structural issues create a significant degree of emotional processing for teachers and administrators. Conversations centered on pedagogy, best practices, and improvement are easily pushed aside to accommodate the chronic anxiety teachers face should they fall victim to one of these structural flaws. Our public-school employees are in a constant state of chronic anxiety from either the structural system of schooling (money, evaluations, ratings, etc.) or from the natural evolution of teaching and learning strategies.

Nationally, we see the same dynamics in play, albeit with different names and slightly different concepts in use. Since Sputnik, American education has become a political football, and American educators unfortunate actors in a constant back-and-forth between the left and right elements of the political spectrum (Hartmann, 2013). We see a national reduction of people wanting to enter the field of teaching, with $54 \%$ of parents saying they would not want their child to enter the field of education (Heller \& Preston, 2018; "Teacher Shortage is 'Real and Growing, and Worse than We Thought," 2019). This mirrors the national principal and superintendent shortages (Sabina, 2014). Figure 4 below, perhaps illustrates best the conundrum of public education nationally. Figure 4, from the Phi Delta Kappan 2018, 50th Annual Poll of the Public's Attitudes Toward the Public Schools, shows that parents give their child's school a relatively high grade. However, their 
opinion drops as they consider other schools in their community or at the state or national level. While parents think their child's school may be achieving at an " $\mathrm{A}$ " or " $\mathrm{B}$ " level, there is less urgency placed on state and national legislators to fix a broken funding and policy system at those respective levels.

Figure 4. From 50 th Annual Poll of the Public's Attitude Toward the Public Schools (p. K21)

\section{Grading the schools}

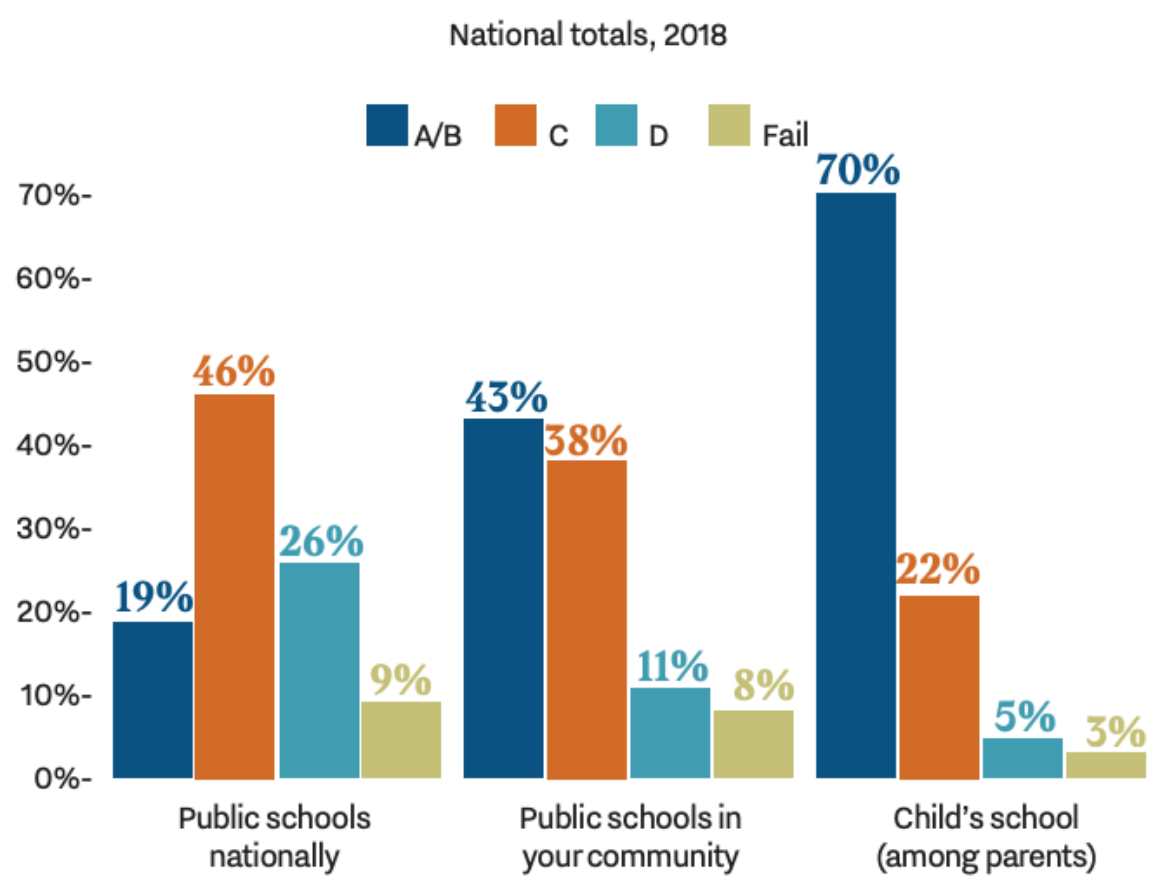

PDK poll, 2018

\section{Conclusion}

To their credit, our nation's teachers continue to give $110 \%$ every day. They do their best not to let kids down and, despite the odds mentioned earlier, continue to inspire our nation's future. Yet the stressors they're facing will not soon go away. In our small corner of the country, in suburban Ohio, I believe that the introduction of the Resilient Leadership framework has helped us understand and emotionally process the world around us, while also moving our practice forward, seemingly despite all odds. Change is risky for leaders and terrifying for everyone else. We have found that our use of Resilient Leadership has reduced our fears and provided valuable insight into the hidden world of emotional systems. This experience has had so much impact through our journey that every school and teacher should further explore emotional differentiation as a critical skill. It has helped many of our educators, leaders, and students, and I hope that you also find equal amounts of insight and guidance. 


\section{References}

Brackett, M. A., Palomera, R., Mojsa-Kaja, J., Reyes, M. R., \& Salovey, P. (2010). Emotion-regulation ability, burnout, and job satisfaction among British secondary-school teachers. Psychology in the Schools, 47(4), 406-417. https://doi.org/10.1002/pits.20478

Bryk, A., \& Schneider, B. (2002). Trust in schools: A core resource for improvement. New York, NY: Russell Sage Foundation.

Collins, J. (2011a). Good to great: Why some companies make the leap...and others don't. New York, NY: Harper Collins.

Collins, J. (2011b). Good to great and the social sectors: A monograph to accompany good to great. New York, NY: Harper Collins.

Duggan, B., \& Moyer, J. (2010). Resilient Leadership. Conshohocken, PA: Infinity Publishing.

Duggan, B., \& Theurer, B. (2017). Resilient leadership 2.0: Leading with calm, clarity, and conviction in anxious times. CreateSpace Independent Publishing Platform.

Finley, S. J. (2000). Instructional coherence: The changing role of the teacher. Southwest Educational Resource Lab.

Friedman, E. H. (2007). A failure of nerve: Leadership in the age of the quick fix. New York, NY: Church Publishing, Inc.

Hanson, R. (1987). History of Stow schools. A dream come true.

Hartmann, J. D. (2013). How school administrators use strategy-as-practice to achieve organizational coherence [University of Pittsburgh ETD]. http://d-scholarship.pitt.edu/18643/

Heifetz, R. A., \& Linsky, M. (2002). Leadership on the line: Staying alive through the dangers of leading. Brighton, MA: Harvard Business School Press.

Heifetz, R. A., Grashow, A., \& Linsky, M. (2009). The practice of adaptive leadership: Tools and tactics for changing your organization and the world. Brighton, MA: Harvard Business Press.

Heller, R., \& Preston, T. (2018). The 50th annual poll of the public's attitudes toward the public schools. Phi Delta Kappan, 24.

Jenkins, C. (2016, September 4). Student killed by Norton school bus remembered as "awesome person.” Akron Beacon Journal. https://www.Beaconjournal.com/akron/news/top-stories-news/student-killed-by-nortonschool-bus-remembered-as-awesome-person

Jennings, P. A., \& Greenberg, M. T. (2009). The prosocial classroom: Teacher social and emotional competence in relation to student and classroom outcomes. Review of Educational Research, 79(1), 491-525. JSTOR.

Jones, S. M., Bouffard, S. M., \& Weissbourd, R. (2013). Educators' social and emotional skills vital to learning. Phi Delta Kappan, 94(8), 62-65. https://doi.org/10.1177/003172171309400815

Kaslow, F., \& Figley, C. R. (1995). Family therapy: Concepts and methods (Book). American Journal of Family Therapy, 23(3), 281-282.

Kotter, J. P. (1995). Leading change: Why transformation efforts fail.

LaRocco, J. M., House, J. S., \& French Jr, J. R. (1980). Social support, occupational stress, and health. Journal of Health and Social Behavior, 202-218.

Loveless, T. (1998). The use and misuse of research in educational reform.

National Defense Education Act (Public Law 85-864). (1958). U.S. Government Printing Office.

Sabina, L. (2014). Factors Influencing Elements of Stress and Autonomy and Control Among School Administrators [University of Pittsburgh ETD]. http://d-scholarship.pitt.edu/23446/

Skaalvik, E., \& Skaalvik, S. (2017). Dimensions of teacher burnout: Relations with potential stressors at school. Social Psychology of Education, 20(4), 775-790.

Steinke, P. L. (2018). Uproar: Calm leadership in anxious times. Lanham, MD: Rowman \& Littlefield.

Teacher Shortage is "Real and Growing, and Worse than We Thought." (2019, April 3). NEA Today. http://neatoday.org/2019/04/03/how-bad-is-the-teacher-shortage/

Travers, C. J., \& Cooper, C. L. (1993). Mental health, job satisfaction and occupational stress among UK teachers. Work \& Stress, 7(3), 203-219.

Urycki, M. (2017, April 25). Ohio school funding unequal 20 years after Supreme Court case. https://www.ideastream.org/stateimpact/2017/04/25/ohio-school-funding-unequal-20-years-after-supremecourt-case

Wagner, T., Kegan, R., Lahey, L. L., Lemons, R. W., Garnier, J., Helsing, D., Howell, A., \& Rasmussen, H. T. (2012). Change leadership: A practical guide to transforming our schools. Hoboken, NJ: John Wiley \& Sons. 
Woods, D. (2002). Moving forward...from where you are to school improvement that lasts: A research-based guide. Yong, Z., \& Yue, Y. (2007). Causes for burnout among secondary and elementary school teachers and preventive strategies. Chinese Education \& Society, 40(5), 78-85. 